Самбетбаева Айгуль, кандидат технических наук Казахская головная архитектурно-строительная академия

г. Алматы, Казахстан

E-mail: aigultdo@mail.ru

ORCID ID 0000-0003-1349-2887

\title{
ОПРЕДЕЛЕНИЕ ТЕРМОСТОЙКОСТИ АНТИКОРРОЗИОННЫХ ПОКРЫТИЙ
}

\author{
Aigul Sambetbaeva, candidate of technical sciences \\ Kazakh Leading Academy of Architecture and Civil Engineering \\ E-mail: aigultdo@mail.ru \\ ORCID ID 0000-0003-1349-2887
}

\section{DETERMINATION OF HEAT RESISTANCE OF ANTI-CORROSION COATINGS}

Annotation: In this article, in order to identify the causes of the influence on the heat resistance of the type of fillers, experiments were carried out to determine the heat resistance of coatings according to the Martens method. It is shown that when exposed to an open flame on a protected sample, a coating based on epoxy resin, where the filler was expanded clay dust, possesses high heat resistance.

Keywords: heat resistance, anti-corrosion coating, filler, epoxy resin.

Аннотация: В данной статье $c$ целью выявления причин оказывающих влияние на жаростойкость вида наполнителей, были проведень эксперименть по определению термостойкости покрытий по методике Мартенса. Показано, что при воздействии открытого пламени на защцищенный образец, высокой термостойкостью обладает покрытие на основе эпоксидной смоль, где наполнителем была керамзитовая пыль.

Ключевые слова: термостойкость, антикоррозионные покрытия, наполнитель, эпоксидная смола.

Известно, что защитные свойства антикоррозионных покрытий определяются суммой физико-химических свойств, которые зависят не только от состава композиции, но и от других, например, технологических факторов, толщины защитной пленки и др.

Покрытия на основе жидкого стекла и минеральных наполнителей, хотя и обладают достаточной адгезионной прочностью и защитной способностью, являются более хрупкими, т.е. они имеют сравнительно низкую ударную прочность в сравнении с покрытиями на основе эпоксидной смолы.

Эпоксидные покрытия обладают высокими защитными свойствами в различных агрессивных средах, однако, их защитные свойства при воздействии на них высоких температур, сравнимых с температурой при пожаре, не исследованы. Поэтому представляет интерес исследовать защитный эффект эпоксидных покрытий при воздействии на них температуры порядка $900^{\circ} \mathrm{C}$ в сравнении с известными эпоксидными составами.

На основании предварительных экспериментов, из многих факторов, влияющих на защитную способность полимерных покрытий, были выбраны: основные параметры температура, ${ }^{\circ} \mathrm{C}$ возможная при пожаре, время термического воздействия, мин; толщина защитной, пленки и вид наполнителя.

Особое значение при разработке защитных покрытий приобретает вид связующего и наполнителя, способ нанесения покрытия и толщина покрытия. Правильный выбор этих

Определение термостойкости антикоррозионных покрытий
Материалы Международной практической интернет-конференции «Актуальные Проблемы Науки» 
параметров позволяет повысить надежность защиты [1], оптимальные значения адгезии [2] и высокий экономический эффект.

На рисунке 1 приведены кривые, показывающие влияние вида наполнителя и толщины покрытий на их жаростойкость при температуре $900-950^{\circ} \mathrm{C}$.

Из рисунка видно, что жаростойкость покрытий на основе эпоксидной смолы и керамзитовой пыли выше, чем у покрытий, где в качестве наполнителя применялся стеклянный порошок (при одинаковой толщине покрытий). При этом с увеличением толщины покрытий значительно повышается жаростойкость, которая доходит до 60 минут при толщине покрытий 1,0 мм. В случае применения в качестве наполнителя стеклянного порошка жаростойкость ниже и находится в пределах 40-45 минут.

Жаростойкость покрытий на основе жидкого стекла и керамзитовой пыли почти одинаков, с жаростойкостью покрытий на основе эпоксидной смолы. Похожая тенденция наблюдается и при использовании в качестве наполнителя стеклянного порошка, где жаростойкость находится в пределах 35-38 минут.

Из рисунка также видно, что перегиб в сторону повышения жаростойкости покрытий отмечается при толщине покрытий 0,6 мм, и плавно возрастает до толщины 1,0 мм.

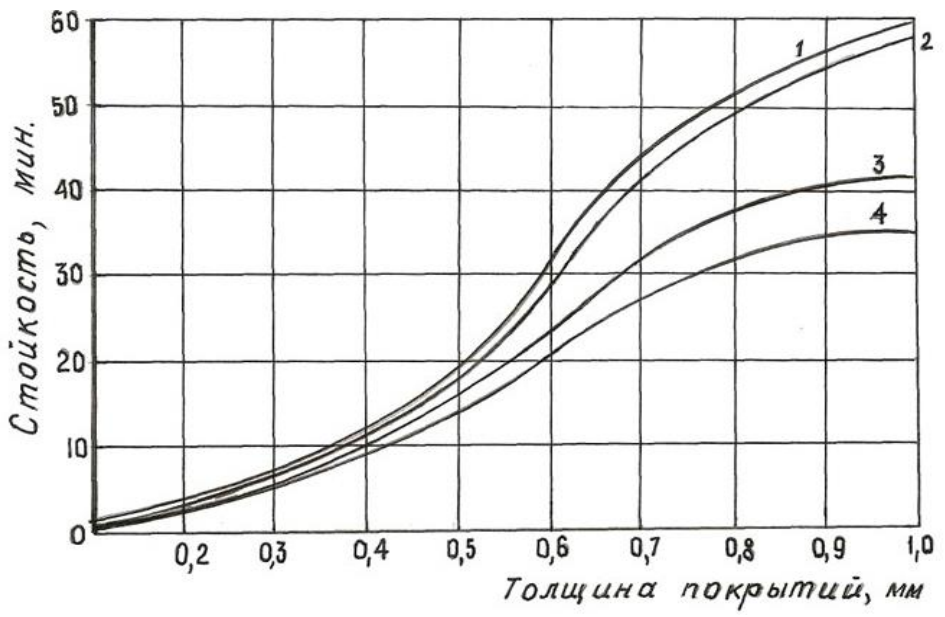

Рисунок 1 - Влияние вида наполнителя и толщины покрытий на жаростойкость

1 - покрытие на основе эпоксидной смоль ЭД-16, наполненной керамзитовой пылью; 2 - то же, на основе жидкого стекла, наполненной керамзитовой пылью; 3 - покрытие на основе эпоксидной смоль ЭД-16, наполненной стеклянным порошком; 4 - то же, на основе жидкого стекла, наполненной керамзитовой пылью.

С целью выявления причин оказывающих влияние на жаростойкость вида наполнителей, были проведены эксперименты по определению термостойкости покрытий по методике Мартенса с той лишь разницей, что вместо нагрева образцов в термошкафу, на образцы воздействовали открытым пламенем от бензиновой горелки. Температуру контролировали лазерным пирометром, и она была в пределах $900-950^{\circ} \mathrm{C}$, т.е. соответствовала температуре, при которой испытывали образцы на жаростойкость покрытий. Покрытие считается термостойким, если испытуемый образец (покрытый стержень) опустился на 6 мм. При этом следует отметить, что испытания проводились на открытом воздухе в течение 1 часа, т.е. присутствовал фактор ветра.

Наши эксперименты показали, что при воздействии открытого пламени на защищенный образец, высокой термостойкостью обладает покрытие на основе эпоксидной смолы, где

Определение термостойкости антикоррозионных покрытий
Материалы Международной практической интернет-конференции «Актуальные Проблемы Науки» 
наполнителем была керамзитовая пыль. Деформация образца не превышала 1,2 мм. Образец с защитным покрытием на основе эпоксидной смолы, наполненной стеклянным порошком, при этих испытаниях деформировался на величину 5-6 мм.

Аналогичные испытания, проведенные с защитным покрытием на основе жидкого стекла и керамзитовой пылью показали деформацию образцов на величину 6-7 мм, а наполненные стеклянным порошком деформировались до величины 9-11 мм.

Значительную деформацию стальных образцов, защищенных антикоррозионными покрытиями на основе жидкого стекла объясняем тем, что покрытие потрескалось, и его компоненты сдувались пламенем горелки. При этом керамзитовая пыль не успевала приобрести пиропластического состояния, и также выдувалось пламенем горелки, как и наполнитель из стеклянного порошка. Вероятно, это также объяснимо, так как в составе покрытия, изготовленного на основе жидкого стекла, присутствует вода, которая при высокой температуре испаряется, увеличиваясь в объеме, и разрывает пленку покрытия. В результате покрытие осыпается.

Высокую термическую стойкость покрытия на основе эпоксидной смолы, наполненной керамзитовой пылью, объясняем тем, что керамзитовая пыль достигает пиропластического состояния вследствие того, что в данном покрытии отсутствует вода. Покрытие не трескается, и вспучивается вместе с эпоксидной смолой. При этом установлено, что исходная толщина покрытия увеличилась с 1,0 мм до 5-6 мм, т.е. образовался теплоизоляционный слой, который значительно повысил термостойкость покрытия.

Сравнительно высокую термостойкость покрытия на основе эпоксидной смолы с наполнителем из стеклянного порошка по сравнению с этим же наполнителем на жидкостекольном связующим, мы также объясняем отсутствием в воды в покрытии, изготовленном на основе эпоксидной смолы.

Таблица 1 - Основные физико-механические свойства антикоррозионных покрытий

\begin{tabular}{|c|c|c|c|c|c|c|}
\hline \multirow[t]{2}{*}{$\begin{array}{c}\text { Показатели свойств } \\
\text { покрытий }\end{array}$} & \multicolumn{3}{|c|}{$\begin{array}{c}\text { Антикоррозионное покрытие } \\
\text { на основе ЭД-16, наполнитель } \\
\text { - стеклянный порошок }\end{array}$} & \multicolumn{3}{|c|}{$\begin{array}{c}\text { Антикоррозионное покрытие } \\
\text { на основе ЭД-16, наполнитель } \\
\text { - керамзитовая пыль }\end{array}$} \\
\hline & $\mathrm{M}$ & $\sigma$ & $\mathrm{P}$ & $\mathrm{M}$ & $\sigma$ & $\mathrm{P}$ \\
\hline 1 & 2 & 3 & 4 & 5 & 6 & 7 \\
\hline $\begin{array}{l}\text { Адгезионная } \\
\text { прочность, МПа }\end{array}$ & 17,2 & 3,2 & 96 & 15,7 & 3,9 & 97 \\
\hline $\begin{array}{l}\text { Толщина покрытий, } \\
\text { обеспечивающая их } \\
100 \% \text { сплошность, мм }\end{array}$ & 0,7 & 16 & 98 & 0,7 & 13 & 96 \\
\hline $\begin{array}{l}\text { Прочность пленки } \\
\text { покрытия при ударе, } \\
\text { кг·см }\end{array}$ & 16,0 & 2,9 & 95 & 14,4 & 3,7 & 97 \\
\hline $\begin{array}{l}\text { Предел прочности при } \\
\text { растяжении, МПа }\end{array}$ & 59,15 & 4,3 & 97 & 56,0 & 4,5 & 96 \\
\hline $\begin{array}{l}\text { Относительное } \\
\text { удлинение, \% }\end{array}$ & 4,9 & 0,6 & 96 & 4,7 & 0,5 & 95 \\
\hline $\begin{array}{l}\text { Остаточные } \\
\text { напряжения, МПа }\end{array}$ & 3,5 & 1,1 & 95 & 2,2 & 1,0 & 98 \\
\hline
\end{tabular}

Определение термостойкости антикоррозионных покрытий
Материалы Международной практической интернет-конференции «Актуальные Проблемы Науки» 
Примечание: образцы испытаны через 24 часа после термообработки покрытий; М средние значения показателей свойств покрытий; $\sigma$ - средняя квадратичная погрешность; $\mathrm{P}$ - вероятность попадания истинного значения в доверительный интервал $2 \sigma, \%$

Таким образом, эксперименты показали, что применение керамзитовой пыли в качестве наполнителя более эффективно при эксплуатации металлических конструкций с антикоррозионным покрытием на основе эпоксидной смолы. В этом случае конструкции могут эксплуатироваться и при возможном воздействии на них пожара. Поэтому дальнейшие исследования мы проводили на антикоррозионных покрытиях на основе эпоксидной смолы, наполненных стеклянным порошком или керамзитовой пылью.

Контроль сплошности антикоррозионных покрытий (таблица 2) показал, что на технологической и эксплуатационной стадиях нарушений сплошности известных эпоксидных покрытий и нового антикоррозионного покрытия - не происходит. Нарушение сплошности (3-13\%) возможно лишь при деформации металлического образца при температуре, превышающем $900-950^{\circ} \mathrm{C}$ и времени воздействия высокой температуры более 55-60 мин, а также в результате механических повреждений при транспортировке и монтаже конструкций. Разрушение в последнем случае происходит на границе покрытие-металл, а сплошность покрытий нарушается только в местах непосредственного контакта монтируемых конструкций. При нормальной транспортировке и монтажных работах изделий такие повреждения не имеют места.

Таблица 2 - Сплошность антикоррозионных полимерных покрытий

\begin{tabular}{|c|c|c|c|c|}
\hline \multirow{3}{*}{$\begin{array}{c}\text { Время } \\
\text { и режимы проверки } \\
\text { сплошности }\end{array}$} & \multicolumn{4}{|c|}{ Сплошность покрытий, \% } \\
\hline & \multicolumn{2}{|c|}{$\begin{array}{l}\text { Антикоррозионное } \\
\text { покрытие на основе ЭД-16, } \\
\text { наполнитель - стеклянный } \\
\text { порошок }\end{array}$} & \multicolumn{2}{|c|}{$\begin{array}{c}\text { Антикоррозионное покрытие } \\
\text { на основе ЭД-16, } \\
\text { наполнитель - керамзитовая } \\
\text { пыль }\end{array}$} \\
\hline & 2 & 3 & 4 & 5 \\
\hline $\begin{array}{l}\text { При растяжении подложки } \\
\text { напряжением: } \frac{\sigma_{0,2}}{\sigma_{\hat{A}}}\end{array}$ & $\frac{100}{87}$ & $\frac{100}{91}$ & $\frac{100}{94}$ & $\frac{100}{97}$ \\
\hline $\begin{array}{l}\text { При изгибе образца в } \\
\text { холодном состоянии на } 75 \\
\text { град. }\end{array}$ & 100 & 100 & 100 & 100 \\
\hline $\begin{array}{l}\text { После 4-х лет выдержки в } \\
\text { атмосферных условиях }\end{array}$ & 100 & 100 & 100 & 100 \\
\hline $\begin{array}{l}\text { После термической } \\
\text { обработки при } 900^{\circ} \mathrm{C} \text { в } \\
\text { течение } 55 \text { мин }\end{array}$ & - & - & 87 & 95 \\
\hline $\begin{array}{l}\text { После ускоренных } \\
\text { испытаний в течение } 180 \\
\text { циклов }\end{array}$ & 92 & 96 & 95 & 98 \\
\hline $\begin{array}{l}\text { После ускоренных } \\
\text { испытаний в 3-х \% растворе }\end{array}$ & 85 & 93 & 97 & 100 \\
\hline
\end{tabular}

Определение термостойкости антикоррозионных покрытий
Материалы Международной практической интернет-конференции «Актуальные Проблемы Науки» 
Таким образом, все исследуемые нами полимерные покрытия на основе эпоксидной смолы обладают физико-механическими свойствами, удовлетворяющими требованиям, предъявляемым к защитным покрытиям. Однако по комплексу ценных физико-механических и технологических свойств покрытий следует выделить разработанный нами термостойкий полимерный состав антикоррозионного покрытия на основе эпоксидной смолы, наполненной керамзитовой пылью, который обеспечивает защиту конструкций при воздействии высокой температуры до $900-950^{\circ} \mathrm{C}$.

Проведенные анализы влияния физико-механических свойств покрытий на их защитную способность, позволяют нам сделать вывод о том, что и в условиях ускоренных коррозионных испытаний механизм защитного действия предлагаемых полимерных покрытий имеет электрохимическую природу.

\section{ЛИТЕРАТУРА}

1. Адаскин А.М., Красновский А.Н. Материаловедение и технология металлических, неметаллических и композиционных материалов. М.: ИНФРА-М, 2018.-400 с.

2. Хохлачева Н.М., Ряховская Е.В., Романова Т.Г. Коррозия металлов и средства защиты от коррозии. М: ИНФРА-М, 2017.- 118 с.

Материалы Международной практической интернет-конференции «Актуальные Проблемы Науки» 